\title{
Impact of multiple extragenital warts on quality of life in immune-competent Egyptian adults: a comparative cross-sectional study
}

This article was published in the following Dove Press journal:

Clinical, Cosmetic and Investigational Dermatology

\author{
Eman Salah \\ Department of Dermatology, \\ Venereology and Andrology, Faculty of \\ Medicine, Zagazig University, Zagazig, \\ Egypt
}

Background: Extragenital warts (E-GWs) are common benign skin lesions caused by human papilloma virus. Surprisingly, there is no clear data about the impact of multiple E-GWs on quality of life in immune-competent adult patients in comparison to GWs, which have been frequently reported to exhibit a strong negative impact on life quality.

Patients and methods: This cross-sectional study investigated the impact of multiple E-GWs on quality of life in immune-competent adults as they are more commonly encountered in daily practice than their genital counterpart in the Egyptian population. Hundred patients with multiple E-GWs (aged 18-67 years, 46 females, 54 males) and 100 patients with multiple GWs (aged 18-55 years, 56 females, 44 males) were included. Cause for immune suppression in the patients was not known. A hard copy of the validated Arabic (Egypt) version of Dermatology Life Quality Index (DLQI) questionnaire was used with permission.

Results: The DLQI total scores range was 5-14 with a mean of 11.2 \pm 2.5 in GWs and 1-24 with a mean of $13.0 \pm 5.8$ in E-GWs, which are statistically significant $(P=0.009)$. To our knowledge, this is the first study to evaluate the impact of E-GWs on life quality of immune-competent adults. Conclusion: E-GWs can have a very strong negative impact on patients' daily life. We highly encourage all treating physicians to use the "bio-psycho-social" model when facing patients with E-GWs in an attempt to secure the best life quality for our patients.

Keywords: HPV, DLQI, warts

\section{Introduction}

Viral warts are common lesions caused by human papilloma virus (HPV) that can affect genital and extragenital sites. Currently, different lines of therapy are available; however, there is no best single effective treatment. ${ }^{1}$ Moreover, warts can be very painful depending on their location, socially unacceptable particularly on visible areas and recalcitrant to therapy with subsequent impairment of patients' daily life. ${ }^{2-4}$ Clinically, the appearance of warts is variable and depends to some extent on the type of HPV involved and the anatomical site, e.g., warts on hands and feet (HPV 1, 2, 4, 27, and 57), plane warts (HPV 3, 10), and genital warts (GWs; HPV 6, 11, 16, 18). ${ }^{5}$

Lots of published studies highlighted the negative impact of GWs on psychological well-being and quality of life of affected individuals in different populations. ${ }^{6-8}$ On the other hand, the common incidence of extragenital warts (E-GWs) in our daily practice justifies the need for defining its effect on quality of life for our patients. Surprisingly to our knowledge, there are no previous reports measuring the impact of E-GWs on patients' quality of life in immune-competent adults.
Correspondence: Eman Salah

Department of Dermatology, Venereology and Andrology, Faculty of Medicine, Zagazig University, Zagazig 44519 , Egypt

Tel +20 1004484367

Email esmohamed@zu.edu.eg 
Herein, we aimed to evaluate the impact of E-GWs versus GWs on patients' quality of life in immune-competent adults.

\section{Patients and methods Ethical approvals}

A formal permission to use the validated Arabic (Egypt) version of Dermatology Life Quality Index (DLQI) questionnaire was obtained kindly from Professor Andrew Y Finlay, Department of Dermatology, Cardiff University School of Medicine, Heath Park, Cardiff, UK. The Institutional Review Board and ethical committees of Zagazig University Hospitals approved this study. All subjects gave a written informed consent before enrollment in this study.

\section{Patients}

This study included 100 patients with clinically diagnosed multiple E-GWs and 100 heterosexual patients with multiple GWs. All patients were immune-competent with no history of any cause for immune suppression and recruited from outpatient clinic at Dermatology, Venereology and Andrology Department at Zagazig University Hospitals. The enrolled patients underwent complete history taking including age, sex, involved sites and number of lesions. Patient inclusion criteria were adults ( $\geq 18$ years), suffering from multiple lesions and immune-competent. Patient exclusion criteria were illiterates or patients with disabilities who will be unable to read or understand the questionnaire, solitary lesions, immunocompromised patients and associated both genital/E-GWs. All visiting patients who fitted the study criteria were invited to participate and answer a-given hard copy of the questionnaire. The recruitment period started on July 2015 and ended on March 2017.

\section{Questionnaire}

\section{DLQI scoring algorithm}

This questionnaire includes 10 questions, each with a maximum score of 3 . Thus, the maximum score for DLQI is 30 , which describes the maximum influence on skin-related quality of life. The scoring of each question is as follows: not at all or not relevant or unanswered $=0$, a little $=1$, a lot $=2$ and very much or prevented work or studying $=3$.

\section{DLQI severity scoring}

The meaning of DLQI scores is as follows: $(0-1)=$ no effect at all on patient's life, $(2-5)=$ small effect, $(6-10)=$ moderate effect, $(11-20)=$ very large, $(21-30)=$ extremely large effect. The 10 questions cover 6 aspects of life, which are symptoms and feelings = questions 1 and 2 , daily activities
$=$ questions 3 and 4 , leisure $=$ questions 5 and 6 , work and school $=$ question 7 , personal relationships questions 8 and 9 , and treatment $=$ question 10 .

\section{Statistical analysis}

Data were checked, entered and analyzed using SPSS version 19. Data were expressed as mean \pm SD for quantitative variables, and as number and percentage for categorical variables. Chi-squared $\left(\chi^{2}\right)$ test or Fisher's extract test, $t$-test and ANOVA ( $F$ test) were used when appropriate. $P<0.05$ was statistically significant. Using Epi-Info 6 program and, supposing that quality of life impaired in $50 \%$ of patients with E-GWs, while in $31.8 \%$ of patients with GWs with power of $80 \%$ and confidence interval of $95 \%$, the sample size was determined as 100 of patients in each group.

\section{Results}

This study included 100 patients with multiple E-GWs (46 females and 54 males) and 10 patients with multiple GWs (56 females and 44 males). Both groups included immunecompetent adult subjects without any cause for immune dysfunction. In E-GW group, the age of the subjects ranged from 18 to 67 years with a mean of $38 \pm 13.3$ years, while in the GW group, it ranged from 18 to 55 years with a mean of $29.5 \pm 8.8$ years. Apparently, there was a significant statistical difference regarding age between the 2 groups $(P<0.001)$, which reflects the fact that GWs are more common in more sexually active younger age groups. Also, there was a significant $(P<0.001)$ statistical difference regarding the number of lesions between the two groups with more numerous lesions in GWs group, which is known to have a highly infectious nature even in immune-competent subjects. The most common predilection sites for E-GWs were feet $(45 \%)>$ hands $(41 \%)>$ face $(14 \%)$. Table 1 summarizes the demographic and clinical data of all subjects. The DLQI total score range was 5-14 with a mean of $11.2 \pm 2.5$ in the GW group and 1-24 with a mean of $13.0 \pm 5.8$ in the E-GW group, which is statistically significant $(P=0.009)$ as illustrated in Table 2 and Figure 1. Table 3 and Figure 2 explain the individual scores for each of the 10 DLQI questions with a significant statistical difference between the 2 studied groups regarding (Q1, 2, 3, 4, 6, 7, 8, and 9 " $P<0.001$ ") and (Q5 " $P=0.004)$. $\mathrm{Q} 10$ scores did not show a significant difference between the two groups $(P=0.08)$.

In DLQI, Q1 and Q2 cover the symptoms and feelings accompanying the disease. According to the studied groups, E-GWs are more symptomatic and annoying to patients. Plantar warts lesions were associated with pain or burning in 
Table I Demographic and clinical data

\begin{tabular}{|c|c|c|c|c|c|c|}
\hline \multirow[b]{2}{*}{ Age (years) } & \multicolumn{2}{|c|}{ Genital warts $(n=100)$} & \multicolumn{2}{|c|}{ Extragenital warts $(n=100)$} & \multirow[t]{2}{*}{$t$} & \multirow[t]{2}{*}{$P$} \\
\hline & & & & & & \\
\hline $\bar{x} \pm S D$ & $29.5 \pm 8.8$ & & $38 \pm 13.3$ & & 5.3 & $<0.001$ \\
\hline Range & $18-55$ & & $18-67$ & & & \\
\hline Sex & $n$ & $\%$ & $n$ & $\%$ & $\chi^{2}$ & $P$ \\
\hline Male & 44 & 44.0 & 54 & 54.0 & 2.0 & 0.15 \\
\hline Female & 56 & 56.0 & 46 & 46.0 & & \\
\hline Lesions number & & & & & $t$ & $P$ \\
\hline $\bar{x} \pm S D$ & $12.6 \pm 4.96$ & & $6.5 \pm 3.1$ & & 10.5 & $<0.001$ \\
\hline Range & $8-23$ & & $2-16$ & & & \\
\hline Lesions sites & $\mathrm{n}$ & $\%$ & $\mathrm{n}$ & & $\%$ & \\
\hline Genital & 100 & 100.0 & 0 & & 0.0 & \\
\hline Face & 0 & 0.0 & 14 & & 14.0 & \\
\hline Hands & 0 & 0.0 & 41 & & 41.0 & \\
\hline Feet & 0 & 0.0 & 45 & & 45.0 & \\
\hline
\end{tabular}

Note: Bold text indicate the statistically significant $p$-values.

Abbreviations: $n$, number; $\bar{x}$, mean.

Table 2 DLQI total scores results in genital versus extragenital warts

\begin{tabular}{|c|c|c|c|c|c|c|}
\hline \multirow{2}{*}{$\frac{\text { DLQI scores }}{\bar{x} \pm S D}$} & \multicolumn{2}{|c|}{ Genital warts } & \multicolumn{2}{|c|}{ Extragenital warts } & \multirow[t]{2}{*}{$t$} & \multirow[t]{2}{*}{$\boldsymbol{P}$} \\
\hline & 11.2 & & 13.0 & & & \\
\hline Range & $5-1$ & & $\mathrm{I}-2$ & & 2.63 & 0.009 \\
\hline DLQI total score & $\mathbf{n}$ & $\%$ & $\mathbf{n}$ & $\%$ & $\chi^{2}$ & $P$ \\
\hline No effect & 0 & 0 & 5 & 5.0 & & \\
\hline Small & 12 & 12.0 & 9 & 9.0 & & \\
\hline Moderate & 16 & 16.0 & 9 & 9.0 & 15.45 & 0.003 \\
\hline Very large & 72 & 72.0 & 69 & 69.0 & & \\
\hline Extremely large & 0 & 0 & 8 & 8.0 & & \\
\hline
\end{tabular}

Note: Bold text indicate the statistically significant $p$-values.

Abbreviations: DLQI, Dermatology Life Quality Index; $n$, number; $\bar{x}$, mean.

most cases (73\%) and some patients reported onset of pain after aggressive surgical excisions, which may be explained by disturbed healing and innervation. Also, many patients were embarrassed about their E-GWs, especially on visible sites as hands and face.

Patient Quote 1: "Doc, I hope you can help me to get rid of my warts. I am a teacher and when I am standing it really hurts as if I am standing on a punch of stones or nails for hours"!!

Patient Quote 2: "Well, it is embarrassing even if people do not tell you in face, you can see that look, if you know what I mean! I feel they think that I am filthy".

Q3 and Q4 focus on impairment of daily activities. Plantar warts pushed many patients to avoid walking or standing for long times and to use more comfortable footwear because of pain. Furthermore, some patients with hand warts reported using gloves to avoid infecting others or to hide their disease at work.

Patient Quote 3: "I work in a bakery and its part of my job to use gloves however, I am afraid if may boss may kick me out because of these warts in my hands. So, I always keep my gloves to be safe".
Q5 and Q6 ask about the effects on leisure times. Male patients with plantar warts suffered the most; as soccer ball is very popular in Egypt, it was very hard to play without pain or discomfort. Many patients just avoided social activities that may induce more pain or embarrassment as in case of facial or hand warts.

Patient Quote 4: "Imagine that it was my wedding and I was waiting to have the best pictures with my wife and all what I can think about is my facial warts"!

Patient Quote 5: "I was very happy to be engaged! So, I captured a picture for my hand and the shining ring to post on Facebook, but I had to edit the photo 1st to "virtually" cure my ugly warts".

Q7 is about effects on work or school. Many patients with E-GWs experienced skipping some working days for different reasons such as pain or psychological frustrations about treatment ineffectiveness.

Patient Quote 6: "I have tried every knowns treatment for my warts, but nothing really works! Just thinking about my problem made me to cancel going for work yesterday". 
A

Genital warts

Extragenital warts

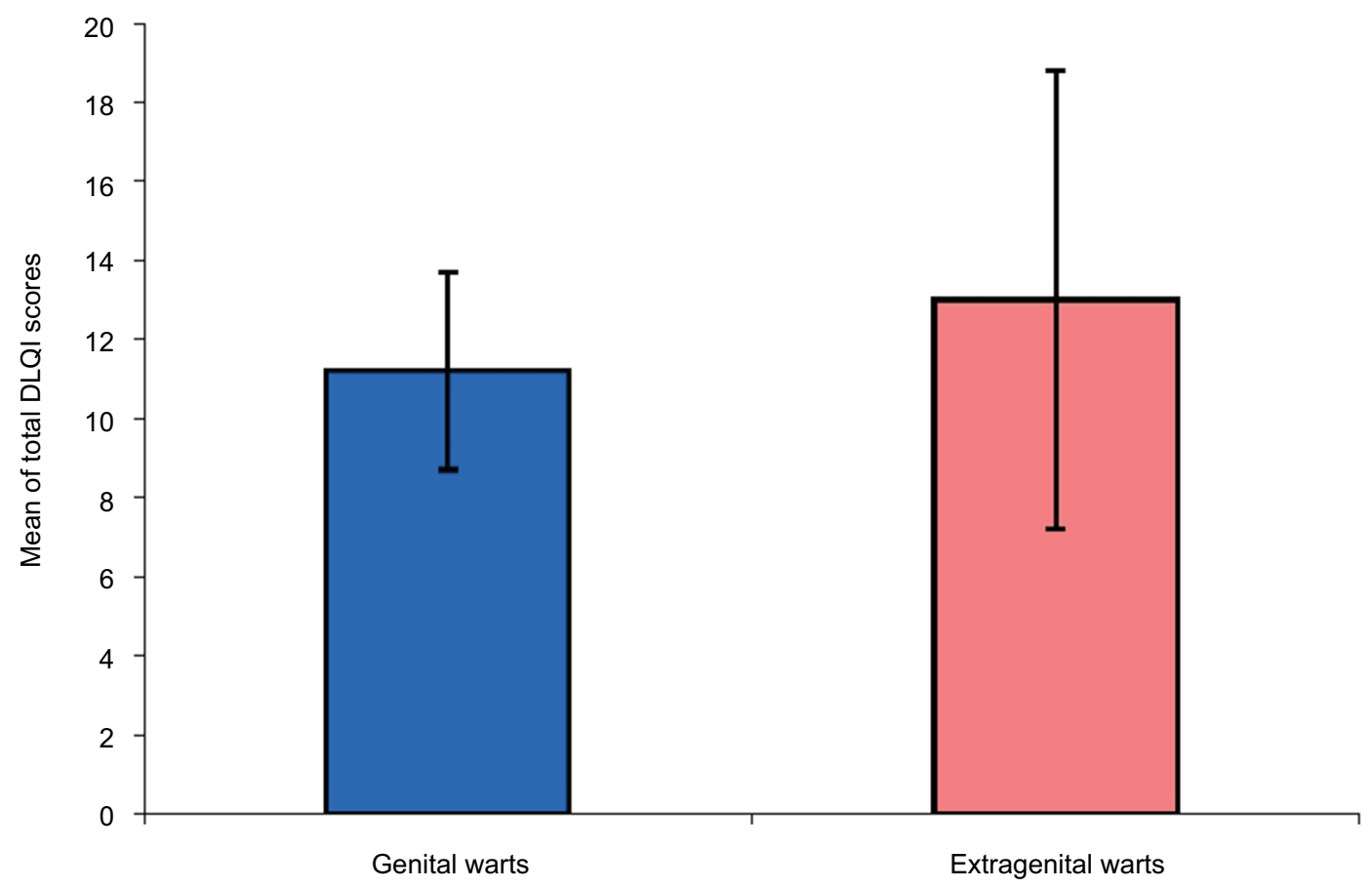

B

Genital warts

Extragenital warts

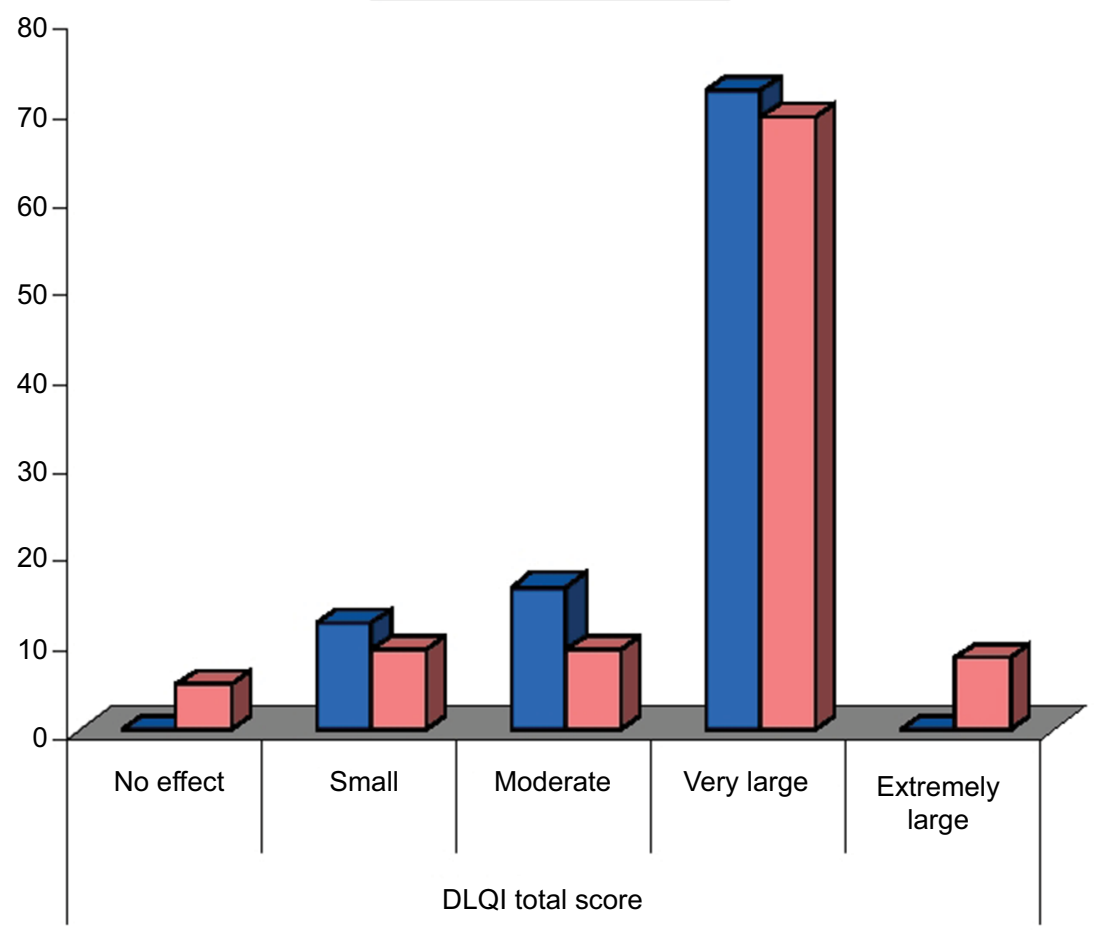

Figure I DLQI total score results in genital versus extragenital warts.

Notes: (A) Total scores: the mean for scores is II.2 \pm 2.5 in genital warts and $13.0 \pm 5.8$ in extragenital warts, which is statistically significant $(P=0.009)$, (B) detailed total scores.

Abbreviation: DLQI, Dermatology Life Quality Index. 
Table 3 DLQI I-I0 questions and answers between the study groups

\begin{tabular}{|c|c|c|c|c|c|c|c|c|c|}
\hline \multirow[b]{2}{*}{$\begin{array}{l}\text { Question } \\
\text { number } \\
\text { "Q" }\end{array}$} & \multicolumn{4}{|c|}{ Genital warts $n=100$} & \multicolumn{4}{|c|}{ Extragenital warts $n=100$} & \multirow{2}{*}{$\begin{array}{l}P \text {-value } \\
\chi^{2} \text { test }\end{array}$} \\
\hline & $\begin{array}{l}\text { Not at all or } \\
\text { Not relevant or } \\
\text { Unanswered \% }\end{array}$ & $\begin{array}{l}\text { A little } \\
\%\end{array}$ & $\begin{array}{l}\text { A lot } \\
\%\end{array}$ & $\begin{array}{l}\text { Very } \\
\text { much } \\
\%\end{array}$ & $\begin{array}{l}\text { Not at all or } \\
\text { Not relevant or } \\
\text { Unanswered \% }\end{array}$ & $\begin{array}{l}\text { A little } \\
\%\end{array}$ & $\begin{array}{l}\text { A lot } \\
\%\end{array}$ & $\begin{array}{l}\text { Very } \\
\text { much } \\
\%\end{array}$ & \\
\hline QI & 22 & 44 & 16 & 8 & 22 & 20 & 36 & 22 & $<0.001$ \\
\hline Q2 & 0 & 8 & 56 & 36 & 20 & 40 & 22 & 18 & $<0.001$ \\
\hline Q3 & 76 & 24 & 0 & 0 & 26 & 27 & 25 & 22 & $<0.001$ \\
\hline Q4 & 72 & 28 & 0 & 0 & 33 & 27 & 30 & 10 & $<0.001$ \\
\hline Q5 & 40 & 36 & 24 & 0 & 29 & 29 & 33 & 9 & 0.004 \\
\hline Q6 & 72 & 28 & 0 & 0 & 36 & 24 & 20 & 20 & $<0.001$ \\
\hline Q7 & 80 & 20 & 0 & 0 & 34 & 38 & 28 & 0 & $<0.001$ \\
\hline Q8 & 4 & 24 & 20 & 52 & 33 & 24 & 28 & 15 & $<0.001$ \\
\hline Q9 & 8 & 20 & 20 & 50 & 56 & 15 & 25 & 4 & $<0.001$ \\
\hline Q10 & 12 & 32 & 20 & 36 & 11 & 18 & 31 & 40 & 0.08 \\
\hline
\end{tabular}

Note: Bold text indicate the statistically significant $p$-values. Abbreviation: DLQI, Dermatology Life Quality Index.

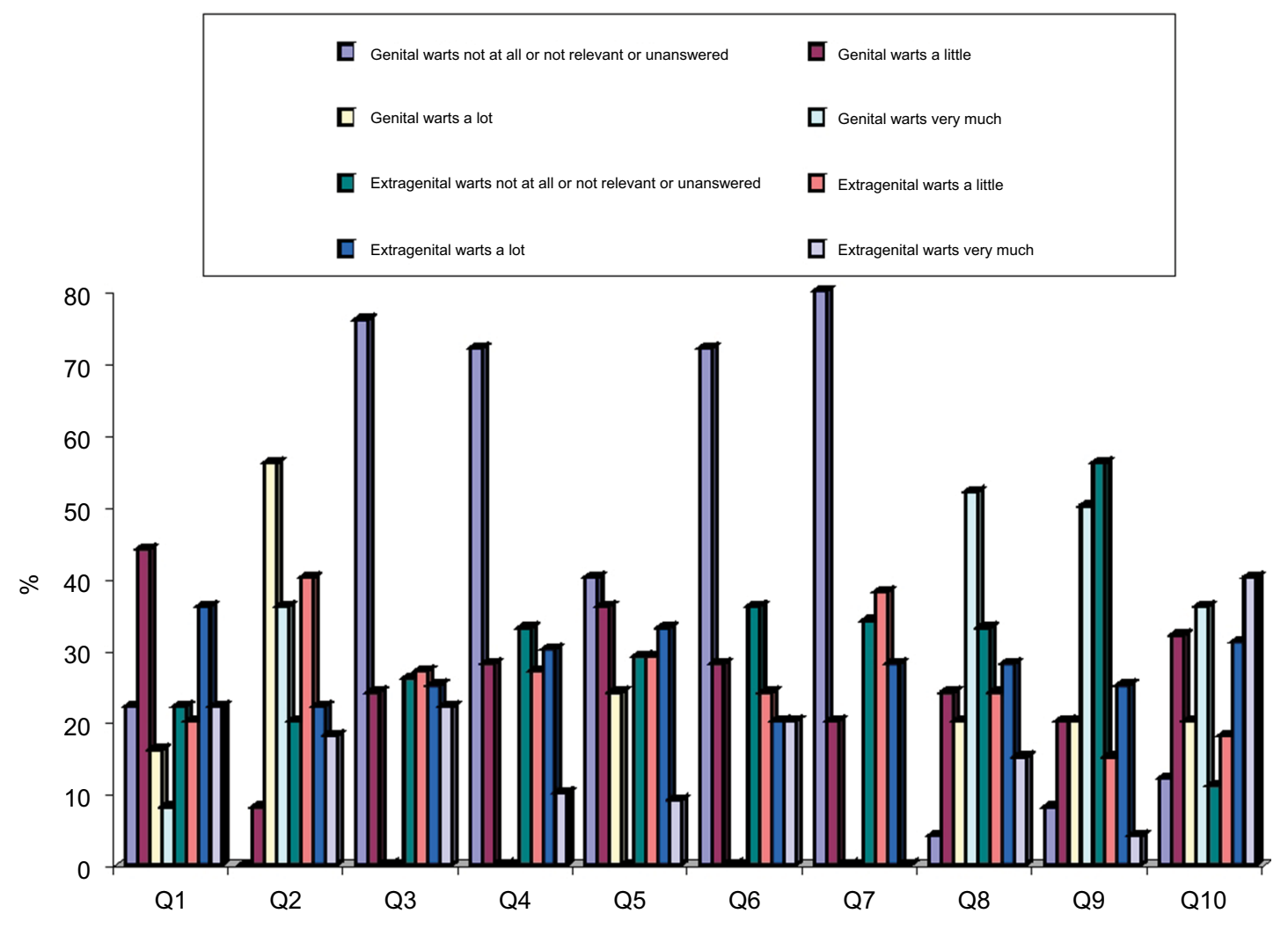

Figure 2 DLQI I-10 questions and answers between the study groups. Abbreviation: DLQI, Dermatology Life Quality Index; Q, question.

Q8 and Q9 inquire about interpersonal relationships. E-GWs exhibited significant impairment of personal relations as hand shaking or kissing/cuddling of own kids. Furthermore, E-GWs affected love partners and their sexual lives, e.g., patients with facial warts were worried about infection transmission by touching or kissing, and patients with hand or feet warts also were concerned about infecting their partners during sexual and non-sexual activities.
Patient Quote 7: "You know, after having warts on my face I decided to be careful when playing with my own kid! That really hurts"!

Patient Quote 8: "My friend seemed very suspicious when he asked about the pumps on my hands as I told him those are just "my warts"! Then I was just struggling when he asked, are not these infectious"???

Q10 asks about treatment and its reflection on quality of life. It seems that both GW and E-GW treatment limitations 
and inadequacy affected both groups at a similar extent without a significant statistical difference $(P=0.08)$.

\section{Discussion}

E-GWs are caused by HPV. They are extremely common and benign in nature. E-GWs can resolve spontaneously by natural immunity but this might take months or years to occur. ${ }^{3}$ However, the search for a cure, cosmetic disfigurement, social stigmatization, prevention of viral transmission in the community, symptoms as disabling pain are logical justifications for treating cutaneous warts. ${ }^{9}$ Unfortunately up to date, there is no such curative or surely effective treatment. This can be explained by the fact of current lacking a specific antiviral drug against HPV. Therefore, most treatment options may be tried as an attempt to increase clearance rates and prevent recurrences. ${ }^{10}$

On the other hand, GWs are well known to negatively impact emotional well-being and life quality of affected patients. Intimacy problems, sense of guilt or shame have been repeatedly reported among patients with GWs. ${ }^{11} \mathrm{GWs}$ are not always benign as E-GWs because they are associated with increased cervical cancer risk, especially in immunocompromised patients, which adds more dysfunction to life quality. ${ }^{12}$ Qi et al had emphasized on the importance to establish psychosocial support systems for patients suffering from GWs by re-directing our approach toward a "biopsycho-social" model instead of just a "biomedical" one. ${ }^{13}$

Surprisingly, the present study using DLQI E-GWs demonstrated a more significant impairment of patients' life quality in comparison to GWs in Egyptian patients. Actually, in the original description of DLQI by Finlay and Khan, patients with viral warts recorded a more severe negative impact on life quality than patients with other dermatoses, like acne vulgaris. ${ }^{14}$ However, we could not find enough further data in the literature regarding the impact of E-GWs on immunecompetent patients' life quality. In a study by Zachariae et al, they reported an increase in number of warts and skin tumors in renal transplant recipients "immune-compromised". ${ }^{3}$ Additionally, using DLQI it was found that the tumors impaired patients' quality of life to a greater extent than viral warts themselves. This is very much expected keeping in mind the known benign course of E-GWs when compared to different skin cancers.

Based on our findings, we strongly agree with Finlay and Khan to use DLQI for evaluating patients with viral warts in routine daily practice. Hopefully, this will create a more effective patient-centered approach. ${ }^{14}$ Also, we can suggest to extent the abovementioned recommendations by Qi et al about GWs to E-GWs based on their higher and statistically significant impact on patients' quality of life. ${ }^{13}$

\section{Conclusion}

E-GWs represent the benign pathway for HPV in comparison to genital ones that carry a potential malignant risk. However, E-GWs can have a very strong negative impact on patients' daily life. Subsequently, we highly recommend considering, and acknowledging, the harmful influences of E-GWs on patients' quality of life. As a start, the treating physicians should use the "bio-psycho-social" model when facing patients with E-GWs in an attempt to secure the best life quality for the patients keeping in mind that our obligation is to treat patients as a whole, not just the warts.

\section{Acknowledgments}

The author would like to thank Professor Andrew Y Finlay, Department of Dermatology, Cardiff University School of Medicine, for giving us permission to use DLQI and Professor Hosnia M Ragab, Professor of Community Medicine, Faculty of Medicine, Zagazig University, Egypt, for her great help regarding the statistics of this study.

\section{Disclosure}

The author reports no conflicts of interest in this work.

\section{References}

1. Dall'oglio F, D'Amico V, Nasca MR, Micali G. Treatment of cutaneous warts: an evidence-based review. Am J Clin Dermatol. 2012;13(2): 73-96.

2. Oni G, Mahaffey PJ. Treatment of recalcitrant warts with the carbon dioxide laser using an excision technique. J Cosmet Laser Ther. 2011;13(5): 231-236.

3. Zachariae C, Sand C, Hansen JM, et al. Warts in a cohort of Danish kidney transplanted patients: impact on quality of life. Acta Derm Venereol. 2012;92(6):615-618.

4. Simonart T, de Maertelaer V. Systemic treatments for cutaneous warts: a systematic review. J Dermatolog Treat. 2012;23(1):72-77.

5. Gibbs S, Harvey I. Topical treatments for cutaneous warts. Cochrane Database Syst Rev. 2006;(3):CD001781.

6. Dominiak-Felden G, Cohet C, Atrux-Tallau S, Gilet H, Tristram A, Fiander A. Impact of human papillomavirus-related genital diseases on quality of life and psychosocial wellbeing: results of an observational, health-related quality of life study in the UK. BMC Public Health. 2013;13:1065.

7. van der Snoek EM, Couwenberg SM, Lammers AM, van Loon AM. Anogenital warts: influence on quality of life in Dutch soldiers. Sex Transm Dis. 2013;40(8):650-651.

8. Lee Mortensen G, Larsen HK. Quality of life of homosexual males with genital warts: a qualitative study. BMC Res Notes. 2010;3:280.

9. Ciconte A, Campbell J, Tabrizi S, Garland S, Marks R. Warts are not merely blemishes on the skin: a study on the morbidity associated with having viral cutaneous warts. Australas J Dermatol. 2003;44(3): 169-173.

10. Micali G, Dall'Oglio F, Nasca MR, Tedeschi A. Management of cutaneous warts: an evidence-based approach. Am J Clin Dermatol. 2004;5(5):311-317. 
11. Vriend HJ, Nieuwkerk PT, van der Sande MA. Impact of genital warts on emotional and sexual well-being differs by gender. Int J STD AIDS 2014;25(13):949-955.

12. Wang H, Kindig DA, Mullahy J. Variation in Chinese population health related quality of life: results from a EuroQol study in Beijing, China. Qual Life Res. 2005;14(1):119-132.
13. Qi SZ, Wang SM, Shi JF, et al. Human papillomavirus-related psychosocial impact of patients with genital wart in China: a hospital-based cross-sectional study. BMC Public Health. 2014;14:739.

14. Finlay AY, Khan GK. Dermatology Life Quality Index (DLQI) - a simple practical measure for routine clinical use. Clin Exp Dermatol. 1994;19(3):210-216.
Clinical, Cosmetic and Investigational Dermatology is an international, peer-reviewed, open access, online journal that focuses on the latest clinical and experimental research in all aspects of skin disease and cosmetic interventions. This journal is included on PubMed. The manuscript management system is completely online and includes a very quick and fair peer-review system, which is all easy to use. Visit http://www.dovepress.com/testimonials.php to read real quotes from published authors 